\title{
Abordagem multidisciplinar em paciente com anomalia dentária de desenvolvimento: relato de caso
}

Multidisciplinary approach in a patient with developmental dental anomaly: case report Abordaje multidisciplinario en un paciente con anomalía dental de desarrollo: reporte de caso

\author{
Letícia Lima Fonseca MENDONCCA \\ Leandro Fonseca MENDONÇA² \\ João Pedro Justino de Oliveira LIMÍRIO ${ }^{3}$ \\ Maria Cristina Rosifini ALVES REZENDE ${ }^{4}$
}

\author{
${ }^{\text {I} G r a d u a c ̧ a ̃ o ~ e m ~ O d o n t o l o g i a, ~ U n i v e r s i d a d e ~ E s t a d u a l ~ P a u l i s t a ~(U N E S P), ~ F a c u l d a d e ~ d e ~ O d o n t o l o g i a ~ d e ~ A r a c ̧ a t u b a, ~ 16015-050 ~ A r a c ̧ a t u b a-S P, ~ B r a s i l ~}$ \\ ${ }^{2}$ Cirurgião-Dentista, graduado pela Universidade Estadual Paulista (UNESP), Faculdade de Odontologia de Araçatuba, Araçatuba-SP, Brasil, Especialização em Ortodontia pela \\ Associação Paulista de Cirurgiões-Dentistas (APCD), regional de Bauru-SP, Brasil \\ Orthoclinic, 18900-000 Santa Cruz do Rio Pardo-SP, Brasil \\ ${ }^{3}$ Mestrando, Programa de Pós-Graduação em Odontologia, Universidade Estadual Paulista (UNESP), Faculdade de Odontologia de Araçatuba, 16015-050 Araçatuba-SP, Brasil \\ ${ }^{4}$ Professora Associada, Universidade Estadual Paulista (UNESP), Faculdade de Odontologia de Araçatuba, 16015-050 Araçatuba-SP, Brasil
}

\section{Resumo}

Dentre as anomalias dentárias de tamanho (alterações de tamanho), os dentes microdônticos ou conoides, classificados como microdontia isolada, resultado da proliferação anormal durante a fase de broto na odontogênese, caracterizam-se por coroas clínicas curtas e não raro, sem os pontos de contato. $\mathrm{O}$ incisivo lateral superior o elemento mais afetado por essa alteração que acomete perto de $1,03 \%$ da população, com predileção pelo sexo feminino e em ambos os lados da arcada dentária. Para o tratamento da microdontia devem ser considerados os requisitos funcionais, estéticos, necessidade de extração e o potencial de se intervir com tratamento restaurador (restaurações indiretas ou diretas) e ortodôntico O presente estudo tem por objetivo relatar a realização da transformação de incisivos laterais superiores conóides, em ambos os lados da arcada, em paciente do sexo masculino, após tratamento ortodôntico planejado, no qual foi propositalmente deixado espaço proximal mesial e distal para confecção de restaurações em resina composta.

Descritores: Ortodontia; Anormalidades Dentárias; Estética Dentária.

\section{Abstract}

Among the dental anomalies of size (size changes), microdontic or conoidal teeth, classified as isolated microdontics, resulting from abnormal proliferation during the bud phase in odontogenesis, are characterized by short, often rare clinical crowns without contact. The upper lateral incisor is the element most affected by this alteration, which affects close to $1.03 \%$ of the population, with a preference for females and on both sides of the dental arch. For the treatment of microdontics, the functional, aesthetic requirements, the need for extraction and the potential to intervene with restorative (indirect or direct restorations) and orthodontic treatment should be considered. , on both sides of the arch, in a male patient, after planned orthodontic treatment, in which the proximal mesial and distal space was deliberately left to make composite resin restorations.

Descriptors: Orthodontics; Tooth Abnormalities; Esthetics, Dental.

\section{Resumen}

Entre las anomalías dentales del tamaño (cambios de tamaño), los dientes microdonticos o conoides, clasificados como microdonticos aislados, resultantes de una proliferación anormal durante la fase de yema en la odontogénesis, se caracterizan por coronas clínicas cortas, a menudo raras, sin contacto. El incisivo lateral superior es el elemento más afectado por esta alteración, que afecta a cerca del $1,03 \%$ de la población, con preferencia por las hembras y en ambos lados del arco dental. Para el tratamiento de la microdoncia, se deben considerar los requisitos funcionales, estéticos, la necesidad de extracción y el potencial de intervención con restauraciones (restauraciones indirectas o directas) y tratamiento de ortodoncia, en ambos lados del arco, en un paciente masculino, después de un tratamiento de ortodoncia planificado, en el que se dejaron deliberadamente los espacios mesial proximal y distal para realizar restauraciones de resina compuesta.

Descriptores: Ortodoncia; Anomalías Dentarias; Estética Dental.

\section{INTRODUÇÃO}

Diversos genes jogam papel na determinação do número, forma, tamanho e posição de cada elemento dentário em um indivíduo. Quando, em razão de fatores patológicos, metabólicos ou ligados a variações ambientais, ocorrem mutações nesses genes, o resultado são anomalias dentárias de desenvolvimento: de número, forma ou estrutura ${ }^{1,2}$.

Dentre as anomalias dentárias de tamanho (alterações de tamanho), os dentes microdônticos ou conoides, classificados como microdontia isolada ${ }^{3,4}$ resultado da proliferação anormal durante a fase de broto na odontogênese, caracterizam-se por coroas clínicas curtas e não raro, sem os pontos de contato ${ }^{5}$. $\mathrm{O}$ incisivo lateral superior o elemento mais afetado por essa alteração que acomete cerca de $1,03 \%$ da população, com predileção pelo sexo feminino e em ambos os lados da arcada dentária 6 . Os dentes conoides afetam negativamente a harmonia e os padrões estéticos do sorriso, conferindo ao paciente adulto um sorriso bastante infantil, demandando para sua resolução, planejamento estético e funcional que envolva a integração de diversas especialidades da Odontologia ${ }^{3,7}$.

De um modo geral, a cor, a forma e a textura de superfície dos elementos dentários se destacam na estética, de forma a caracterizar e personalizar o sorriso. No entanto, sabemos que é bastante complexa a relação entre o paciente e a imagem que faz de si mesmo, bem como a maneira como ele gostaria de ser visto por seu grupo social ${ }^{1}$.

Segundo Andrade et al. $^{8}$ as alterações dentárias do desenvolvimento se apresentam ao cirurgião-dentista de forma incidental, nas consultas de rotina, ou por insatisfação do paciente com sua estética, cabendo ao profissional não só saber diagnosticar, como também traçar o plano de tratamento mais adequado para cada caso.

Para o tratamento da microdontia devem ser considerados os requisitos funcionais, estéticos, necessidade de exodontia e o potencial de se intervir com tratamento restaurador (restaurações indiretas ou diretas) e ortodôntico 5 . 
O propósito deste trabalho é relatar abordagem multidisciplinar envolvendo ortodontia e dentística para o tratamento de paciente com incisivos laterais superiores conoides e diastemas.

\section{CASO CLÍNICO}

Paciente 14 anos e 8 meses de idade, sexo masculino, melanoderma, procurou tratamento ortodôntico em clínica especializada para solucionar várias intercorrências que estavam prejudicando sua oclusão e estética: 1) Dente 13 retido e presença do 53 no local 2) Havia sofrido exodontia dos dentes 36 e 46 com outro profissional, por problema de lesão cariosa extensa. 3) Dentes 12 e 22 conóides 4) Mordida cruzada anterior e posterior direita 5) Palato atrésico 6) Desvio linha média mandibular para direita 7)Respirador bucal 8) Diastemas anteriores superiores 9) Maxila e mandíbula retruídas em relação à base do crânio/ Padrão de crescimento vertical (Figuras 1 a 6)

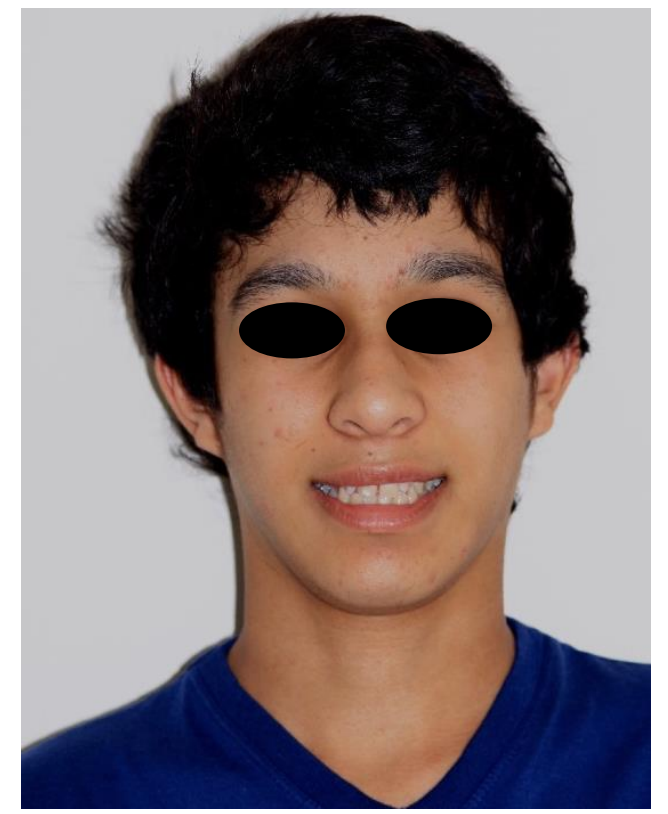

Figura 1: Fotografia extrabucal do paciente (sorriso).

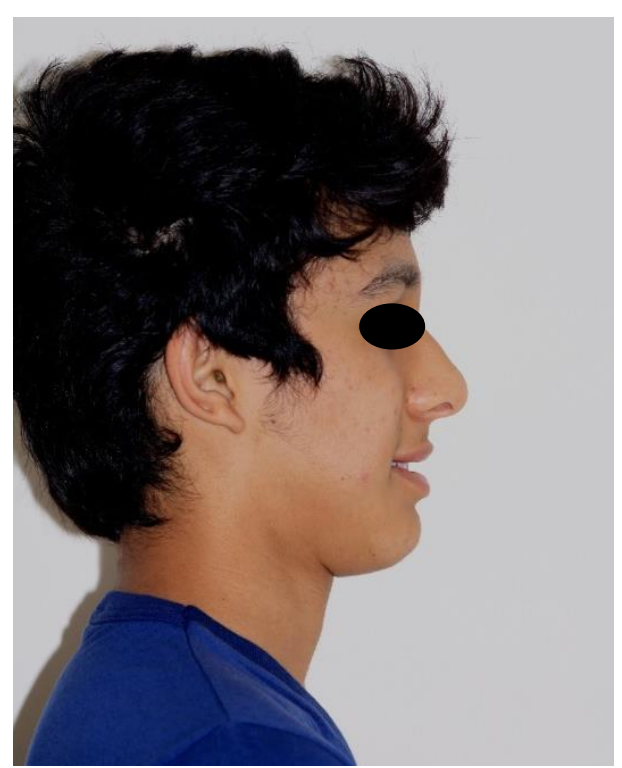

Figura 2: Fotografia extrabucal do paciente (perfil).

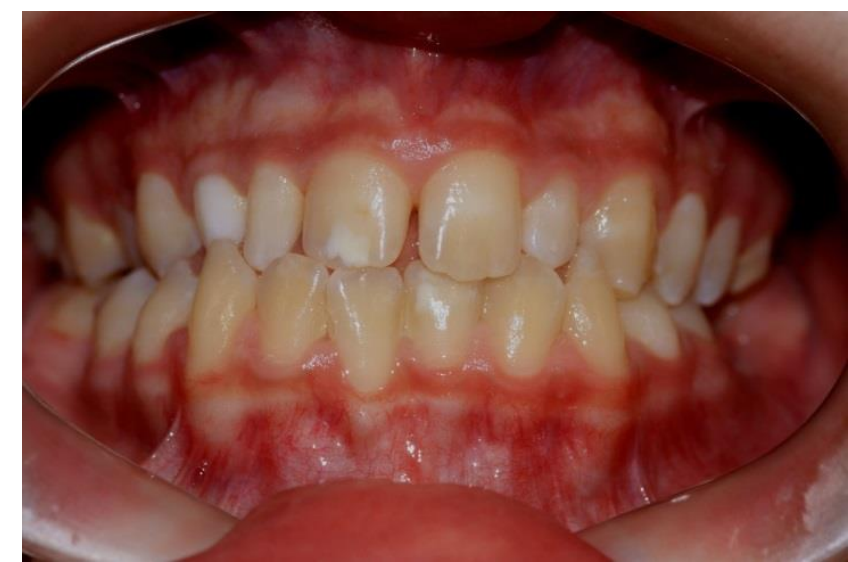

Figura 3: Fotografia intrabucal (vista frontal).

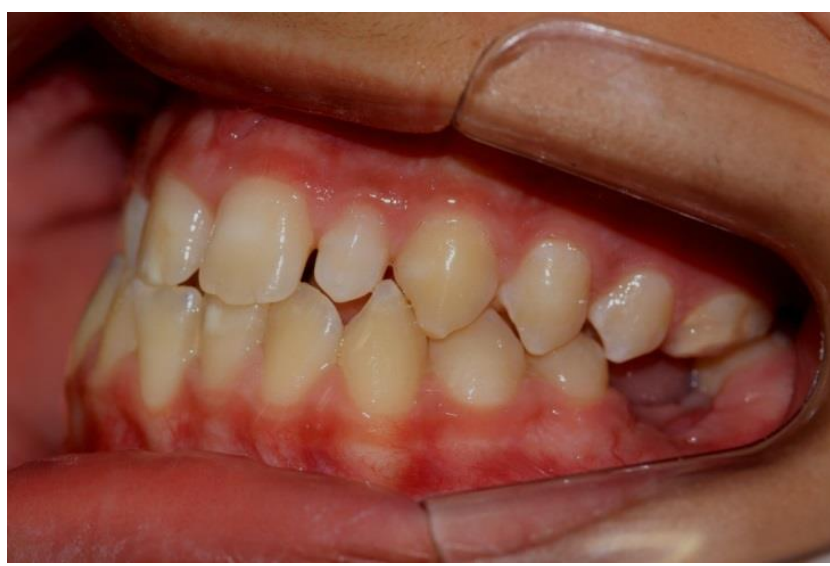

Figura 4: Fotografia intrabucal (vista lateral esquerda).

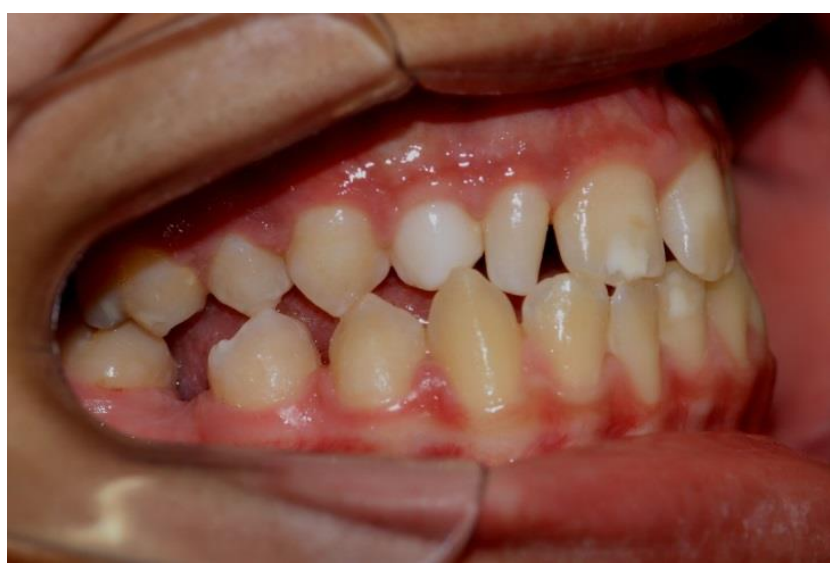

Figura 5: Fotografia intrabucal (vista lateral direita).

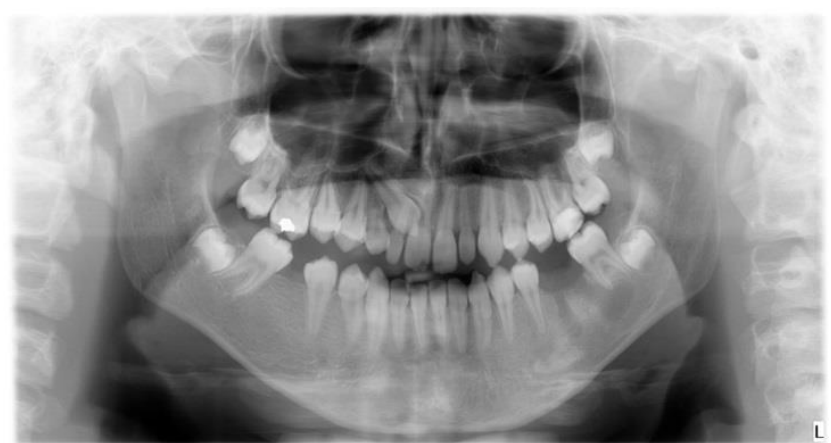

Figura 6: Radiografia panorâmica inicial.

A análise da radiografia panorâmica inicial apresentou achados compatíveis com germe dentário (18,28,38 e 48); elementos ausentes (36 e 46); elemento retido (13); suspeita de dilaceração radicular; presença de elemnto decíduo (53); 
microdontia (12 e 22); côndilos mandibulares direito e esquerdo com textura óssea, contornos e formas regulares; além de, em relação aos seios maxilares, extensão alveolar e para o tuber esquerdo e direito (Figura 7).

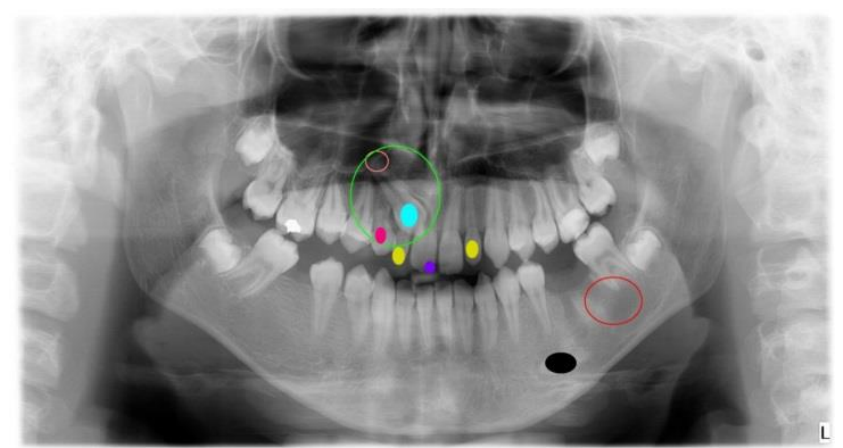

Figura 7: Radiografia panorâmica (achados radiográficos).

Foi planejado: 1) Disjunção rápida da maxila com aparelho disjuntor de Hass 2) Tratamento Ortodôntico corretivo com aparelho auto ligado metálico e fios termo-ativados 3) Tracionamento cirúrgico 13 4) Tracionamento 37 e 47 com mini implantes 5) Reconstrução coroa clínica 12 e 22 com resina fotopolimerizável 6) Correção linha média mandibular 7) Correção mordida cruzada.

O tratamento restaurador (reconstrução da coroa clínica do 11 e 22) foi realizado com resina composta, imediatamente após a remoção do aparelho ortodôntico no arco superior (Figura 8).

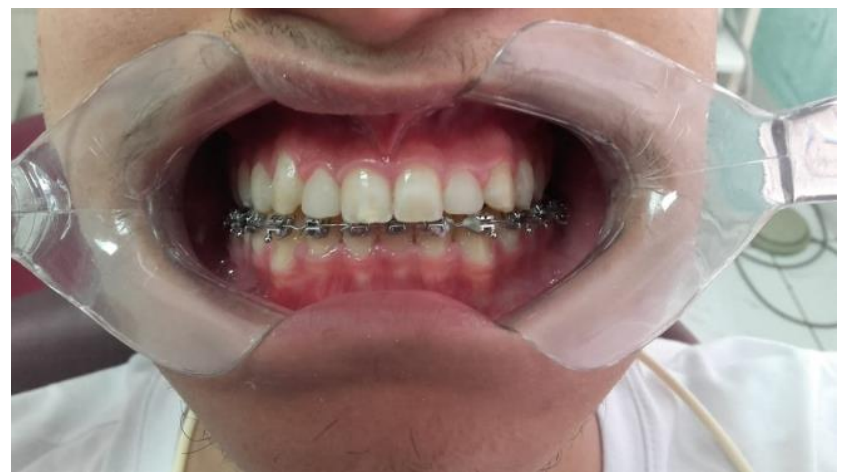

Figura 8: Arco superior finalizado após tratamento ortodôntico e restaurador.

\section{DISCUSSÃO}

Segundo Ricketts ${ }^{9}$ e Rosa e Zachrisson ${ }^{10}$, o equilíbrio funcional e facial, objetivo do tratamento ortodôntico, implica na observância de princípios macroestéticos, tais como linha do sorriso, linha gengival, linha média, inclinação do plano oclusal e curva do sorriso.

Kajewski ${ }^{11}$ lembra que se discrepâncias no tamanho das coroas clínicas não forem observadas no planejamento ortodôntico resultarão em diastemas na bateria anterior ao final do tratamento, consequência da desproporção áurea ${ }^{10,12}$.

A abordagem integrada envolvendo ortodontia e dentística permite que nesses pacientes, espaços não homogêneos entre elementos dentários sejam meticulosamente dispostos, de modo a potencializar intervenção restauradora futura, que traga ao paciente não só harmonização do sorriso como também harmonização facial.

Rosa e Zachrisson ${ }^{10}$ destacam que uma grande vantagem do fechamento do espaço é que, embora a manutenção contínua em longo prazo seja necessária, o resultado do tratamento ortodôntico será permanente.

Reikie $^{13}$ argumenta que o estabelecimento e manutenção da oclusão estável, alcançado na abordagem multidisciplinar do tratamento ortodôntico controlam funcionalmente o prognóstico do caso.

Honores ${ }^{14}$ lembra que nos casos em que há discrepância do tamanho dentário, o tratamento ortodôntico sozinho não é capaz de oferecer os melhores resultados. Portanto, esses diastemas devem ser fechados, isto é, as coroas clínicas devem ser reanatomizados por meio de compósitos, facetas ou coroas protéticas. No entanto, para o melhor resultado estético dessas restaurações, o movimento ortodôntico é essencial na medida em que redistribui os espaços entre os elementos dentários previamente ao procedimento estético ${ }^{15}$.

No presente caso, a análise minuciosa dos parâmetros estéticos do paciente, o que inclui o tamanho das coroas clínicas, previamente ao planejamento ortodôntico contribuiu para a terapia bem sucedida, com resultado estético e funcional que potencializam a qualidade de vida do paciente. Corroborando com Kajewski ${ }^{11}$, que atribui à analise do tamanho dental a possibilidade de diagnóstico mais completo, capaz de proporcionar planejamento mais adequado e interdisciplinar, aumentando o índice de sucesso tanto por parte de pacientes como por parte de profissionais.

\section{CONCLUSÃO}

No caso apresentado, a perspectiva interdisciplinar de diagnóstico e tratamento permitiu resultado estético e funcional favorável, com ganhos para os parâmetros de qualidade de vida do paciente. A abordagem multidisciplinar de conceitos entre a Ortodontia e outras especialidades é de importância crescente na obtenção de alta qualidade nos resultados do tratamento.

\section{REFERÊNCIAS}

1. Mafra RP, Vasconcelos RG, Vasconcelos MG, Queiroz LMG, Barboza CAG. Desenvolvimento dental: aspectos morfogenéticos e relações com as anomalias dentárias do desenvolvimento. Rev Bras Odontol. 2012; 69(2):232-37.

2. Yamunadevi A, Selvamani M, Vinitha V, Srivandhana R, Balakrithiga M, Prabhu S et al. Clinical evaluation of nonsyndromic dental anomalies in Dravidian population: A cluster 
sample analysis. J Pharm Bioallied Sci. 2015;7(2):499-503.

3. Regesi JA, Sciubba JJ. Patologia bucal: correlações clínico-patológicas. Rio de Janeiro: Guanabara Koogan; 1989.

4. Silva SBA, Argenta RMO, Machado R, Basso R. Reconstrução de coroa e recontorno cosmético com resina composta direta em dentes anteriores: relato de caso. RFO UPF. 2003;8(1):34-7.

5. Barros ACRLF. Microdontia e opções de tratamento [dissertação]. Porto: Universidade Fernando Pessoa - Faculdade de Ciências da Saúde; 2013.

6. Pedrini D, Jardim PS, Poi WR. Transformação de denteconóide e fechamento de diastema em clínica geral. Rev Unimep. 2000;1(2):52-6.

7. Veronezi MC, Brianezzi LFF, Modena K, Lima MS, Bernardi SE. Remodelação estética de dentes conoides: tratamento multidisciplinar. RDAPO. 2017;1(1):35-40.

8. Andrade CES, Lima IHL, Silva IVS, Vasconcelos MG, Vasconcelos RG. As principais alterações dentárias de desenvolvimento. Salusvita. 2017;36(2):533-63.

9. Ricketts RM. The biologic significance of the divine proportion and Fibonacci series. Am J Orthod. 1982; 81(5):351-70.

10.Rosa M, Zachrisson BU. Integrating esthetic dentistry and space closure in patients with missing maxillary lateral incisors. J Clin Orthod. 2001;35(4):221-34.

11.Kajewski AD. Fechamento de diastema e correção de lateral conóide utilizando resina composta direta: Relato de caso [monografia especialização]. Curutiba: ILAPEO, 2012.

12.Warren K, Howat AP. Multi-disciplinary treatment planning for the restorative patient. Restorative Dent. 1990;6(4):12-5.

13. Reikie DF. Orthodontically assisted restorative dentistry. J Can Dent Assoc. 2001;67(9):516-20.

14.Honores MJC. Stability of Diastemas Closure after Orthodontic Treatment. Doi 10.572/intechopen. 82480

15.Furuse AY, Franco EJ, Mondelli J. Esthetic and functional restoration for an anterior open occlusal relationship with multiple diastemata: a multidisciplinary approach. J Prosthet Dent. 2008;99(2):91-4.
CONFLITO DE INTERESSES

Os autores declaram não haver conflitos de interesse.

AUTOR PARA CORRESPONDENCIA

Letícia Lima Fonseca Mendonça

leticiamendonca93@hotmail.com

Submetido em 01/03/2019

Aceito em 28/03/2019 